\title{
Vocação regional e design: artes manuais da Região do Médio vale do
}

\section{Itajaí}

\section{Regional vocation and design: handicrafts from the Médio Vale do Itajaí Region}

\author{
Carolina Pianizzer \\ Bacharel em Design de Moda pela Universidade do Vale do Itajaí (UNIVALI) - carolinapianizzer@gmail.com - \\ http://orcid.org/0000-0001-7595-3509 \\ Luciane Ropelatto \\ Mestre em Design pela Universidade Federal de Santa Catarina (UFSC) - lucianerop@hotmail.com - \\ http://orcid.org/0000-0003-4575-0764
}

\section{Resumo}

Apresenta um estudo bibliográfico e de campo acerca da temática sobre a vocação regional e o design, com foco nas artes manuais da região do Médio Vale do Itajaí. Mostra a realidade inserida no processo criativo utilizado por artesãos da região citada. Objetiva analisar a dinâmica do desenvolvimento dos produtos artesanais e dos trabalhos manuais produzidos em cidades do Médio Vale do Itajaí, a fim de identificar a existência ou a ausência do processo criativo de design no desenvolvimento dos produtos. O interesse por esta temática se deu pelo intuito de buscar estudos aprofundados sobre referências regionais no Brasil, visando a realização de uma ação investigativa na área de vocações regionais, ainda incipientes. Como resultado, pôde-se observar a ausência do processo criativo de design no desenvolvimento dos produtos desses profissionais.

Palavras-chave: Artesanato - Brasil. Artesões Brasil. Vocação regional.

\begin{abstract}
It presents a bibliographical and field study about the thematic on the regional vocation and design, focusing on the manual arts of the region of the Middle Vale do Itajaí. It shows the reality inserted in the creative process used by craftsmen of the region cited. It aims to analyze the dynamics of the development of the hadmade and of the manual works produced in cities of the Middle Vale of the Itajaí, to identify the existence or the absence of the creative design process in the development of products. The interest in this theme was given by intention of seeking in-depth studies on the regional references in Brazil, aiming to carry out an investigative action in the area of the regional vocations, still incipient. As a result, it can be observed the absence of the creative design process in the development of the products of these professionals.
\end{abstract}

Keywords: Crafts - Brazil. Craftsmen - Brazil. Regional vocation.

Recebido em: 09/02/2017

Aceito em: 11/03/2019 


\section{INTRODUÇÃO}

O fato de o Brasil ter várias influências étnicas na sua cultura e de ter ampla fonte de referências e diversificadas inspirações, permite aos designers fartas possibilidades e a criação de produtos exclusivos. Além de priorizar pela qualidade, o consumidor está mais exigente e qualificado e busca por produtos com um diferencial, podendo ser, um fator importante na decisão de sua compra. Nos produtos brasileiros, esse diferencial pode ser encontrado como resultado de inspirações regionais, com valorização dos trabalhos manuais e o artesanato. Por meio deles, impulsionam novas ideias, conexões e modelos de negócios, além de preservar o patrimônio cultural do país. A combinação da tradição das práticas artesanais com o design contemporâneo estabelece nos produtos brasileiros um valor com características nacionais próprias. De acordo com Moura (2012, p. 3) "o design brasileiro contemporâneo tem sido marcado e constituído pela fusão dos vários segmentos da área do design ou pelo rompimento de fronteiras", isto é, o trabalho de criação e produção desvinculado dos aspectos tradicionais do design de produto, gráfico, moda ou joia.

Oferecer um novo conceito ao artesanato é um dos papéis do design. A parceria e a troca de informação entre designers e os artesãos tem como benefício a oferta de produtos artesanais com valores conceituais agregados. De acordo com De Carli et al (2011, p. 431), “o artesanato é uma das mais tradicionais formas de manifestação cultural, mas, como tudo que atravessa o tempo, precisa se renovar de alguma maneira". Uma delas é por meio do trabalho do designer ao empregar materiais básicos (muitas vezes já utilizados pelo artesão), observar ícones da cultura local e promover o ofício em grupo, favorece a união das comunidades, conserva a tradição local e valoriza seus produtos. Esse profissional também corrobora com o olhar para o presente e para o mercado, criando parcerias para possibilitar novas ideias e oportunidades, na qual a consequência se dá no fator econômico - o aumento da fonte de renda para muitas famílias.

Em trabalhos ligados às cooperativas, aos grupos de rendeiras e de costureiras, dá-se a prática de técnicas artesanais, tais como crochê, renda, fuxico, bordado e trançado, muitas vezes associadas ao emprego de materiais naturais típicos do país, como alguns tipos de fibras, madeiras e palhas. Nesses locais, o desenvolvimento do produto é, geralmente, feito pelo profissional com completo entendimento da técnica. No entanto, nota-se que por vezes o produto é carente de 
design criativo. Neste contexto, surgiu a questão norteadora da pesquisa: como é a relação entre o design e as técnicas de artesanato no desenvolvimento de produtos realizados por artesãos?

Assim, esse artigo objetiva analisar a dinâmica do desenvolvimento de produtos artesanais e de trabalhos manuais de moda produzidos em cidades do Médio Vale do Itajaí, visando a identificação da existência ou da ausência do processo criativo de design na produção de tais artefatos. Os objetivos específicos centraram-se em mapear a mão de obra artesanal existente no Médio vale do Itajaí e levantar dados indicativos sobre o processo criativo utilizado pelos artesãos.

\section{PROCEDIMENTOS METODOLÓGICOS}

A pesquisa explanada neste artigo teve uma abordagem qualitativa do tipo exploratória, de natureza aplicada. O estudo iniciou com um mapeamento, realizado por meio de pesquisas bibliográficas e contato com as prefeituras dos municípios da região do Médio Vale do Itajaí. Pelas dificuldades de contato e acesso aos profissionais que realizam trabalhos manuais e artesanato, a pesquisa se concentrou nos municípios de Blumenau, Botuverá, Brusque, Gaspar, Guabiruba, Indaial, Pomerode, Rio dos Cedros e Timbó.

Para conseguir informações dos mesmos, foi necessário entrar em contato primeiro com as prefeituras e fundações culturais de cada município, estas passaram os contatos disponíveis em seus bancos de dados. Posteriormente, realizou-se uma entrevista com perguntas abertas semiestruturadas, por meio de ligações telefônicas e pessoalmente, com duração aproximada de 20 minutos. Contou-se com a participação de 23 pessoas, tanto do sexo feminino como masculino, com idade entre 40 e 70 anos. A pesquisa foi realizada no período de 8 de agosto de 2016 a 16 de setembro de 2016, onde foi possível coletar dados e levantar opiniões e atitudes referentes aos profissionais. Definiu-se por não expor a identidade dos entrevistados, optando por intitulá-los com legendas (letras $\mathrm{A}$ a $\mathrm{U}$ ). Os resultados foram organizados em um quadro e inferidos com os conceitos sobre processo criativo definidos pelos autores Ambrose e Harris (2011) e Mozota, Klöpsch e Costa (2011). 


\subsection{Design território e vocação regional}

Segundo Krucken (2009), o design é cada vez mais aceito como uma das ferramentas para a valorização de produtos locais, por proporcionar a preservação de identidades e culturas regionais. O Brasil cresce nesse ramo por ser um país rico em biodiversidade e cultura. Essa riqueza

[...] constitui a base para o desenvolvimento de produtos fortemente ligados à origem e à comunidade local. No entanto, muitas vezes os recursos existentes não são explorados de forma sustentável (econômica, social e ambientalmente) e não geram riqueza e melhoria na qualidade de vida da comunidade local, assim como, de modo mais abrangente, em nível nacional (KRUCKEN, 2009, p. 22).

De acordo com Braga e Nunes (2006, p. 43), "cabe a nós mesmos, brasileiros, nos valorizarmos em primeiro lugar, para que outros povos nos valorizem" e, para tanto, é preciso encontrar um caminho de autenticidade e identidade própria, onde os criadores possam ter o real reconhecimento de produzir um produto inteiramente nacional. Para os autores, no Brasil há ricas referências e, nele, há como buscar inspirações além dos símbolos considerados "tradicionais", por meio de pesquisas em elementos da música, da literatura, da religiosidade, das regiões. Assim, afirmam que precisamos

\footnotetext{
Ir além da aparência verde-amarela e encontrarmos uma identidade para o design brasileiro de moda, resgatando tradições e valorizando a criatividade com o "ar dos tempos", para sermos reconhecidos com muito mais profundidade e solidez do que somente pela combinação das cores (BRAGA; NUNES, 2006, p. 43).
}

Para fugir de elementos caricatos, um dos movimentos mais vistos atualmente é união da tradição das técnicas manuais com o design contemporâneo. O movimento, que representa a cultura e história de uma determinada região, é a inspiração e aplicação de técnicas a partir de artes manuais como forma de marcar a brasilidade, assumindo assim o valor e representação da identidade nacional (BRAGA; NUNES, 2006).

Para Weber (1967), quando se fala de um determinado território a partir de sua "especialização" ou pelo seu "polo" econômico, na maioria das vezes se encontra nesse território união com uma determinada "vocação". Esta vocação regional se apresenta em locais com predomínio de determinada atividade, tanto de ordem natural quanto de ordem cultural da região. Deste modo, Florit (2009) salienta que um componente significativo é a questão da vocação do trabalho com uma ligação divina. Embora a ideia de vocação regional seja de que uma região é 
especialista em uma determinada atividade por motivos culturais do seu território, por fim existem são construções sociais, políticas e históricas.

De acordo com o IBGE (2013a) são muitos os contrastes geográficos, históricos e culturais formadores da cultura no estado de Santa Catarina. No contexto da pesquisa aqui relatada, o Vale do Itajaí é uma das seis mesorregiões brasileiras desse estado. Compreende uma área de $13.003,018 \mathrm{~km}^{2}$, sendo uma mesorregião composta por 54 municípios agrupados em quatro microrregiões. Como microrregiões estão agrupados os municípios que apresentam, entre si, similaridades econômicas e sociais. "Compreende-se 4 microrregiões: Microrregião de Blumenau, Microrregião de Itajaí, Microrregião de Ituporanga e Microrregião de Rio do Sul" (IBGE, 2013a). A microrregião de Blumenau abrange os municípios de Apiúna, Ascurra, Benedito Novo, Blumenau, Botuverá, Brusque, Doutor Pedrinho, Gaspar, Guabiruba, Indaial, Pomerode, Rio dos Cedros e Timbó, situados no Médio Vale do Itajaí, totalizando uma área de 4.754 km² com uma população de 677.553 habitantes.

No estado de Santa Catarina as operações de vocações regionais são diversas. Na região do Médio Vale do Itajaí há o predomínio da vocação para a área têxtil, logo as atividades econômicas e profissionais tendem a se concentrar nesse ramo. Atividades como o artesanato e trabalhos manuais são fortes influências em todos os municípios da região, onde a vocação se apoia, em grande parte, nas características naturais, históricas e culturais do território (IBGE, 2013b).

\subsection{Artesanato e Artes Manuais}

A Portaria no 29, de 05 de outubro de 2010 da Secretaria do Comércio e Serviços do Ministério do Desenvolvimento, Indústria e Comércio Exterior (BRASIL, 2010, p.100), nos Artigo números 4 e 6, apresenta os seguintes conceitos:

ARTESANATO - Artesanato compreende toda a produção resultante da transformação de matérias-primas, com predominância manual, por indivíduo que detenha o domínio integral de uma ou mais técnicas, aliando criatividade, habilidade e valor cultural (possui valor simbólico e identidade cultural), podendo no processo de sua atividade ocorrer o auxílio limitado de máquinas, ferramentas, artefatos e utensílios.

[...]

TRABALHOS MANUAIS - Apesar de exigir destreza e habilidade, a matéria-prima não passa por transformação. Em geral são utilizados moldes pré-definidos e materiais industrializados. As técnicas são aprendidas em cursos rápidos oferecidos por entidades assistenciais. 
A Portaria n.1.007-SEI, de 11 de junho de 2018 no Art. 19 do Ministério da Indústria, Comércio Exterior e Serviços da Secretaria Especial da Micro e Pequena Empresa (BRASIL, 2018) traz o conceito da Atividade Artesanal: "Artesanato é toda produção resultante da transformação de matérias-primas em estado natural ou manufaturada, através do emprego de técnicas de produção artesanal, que expresse criatividade, identidade cultural, habilidade e qualidade" e entende as definições nos parágrafos §1‥ ao §5ㅇ․ No parágrafo § 6으 nos incisos I ao VII, há definições do que não é considerado artesanato - semelhantes aos conceitos definidos como "Trabalhos Manuais" da Portaria n. 29.

Ou seja, o artesanato é uma atividade produtiva provinda do próprio trabalho do artesão, por meio do qual há a transformação da matéria prima, a qual resulta num produto com características culturais. Já o trabalho manual terá um produto obtido como resultado de uma atividade feita à mão, porém podendo ser concebido pelo auxílio de máquinas simples, não precisando ter transformação da matéria prima nem características culturais específicas. Hoje, o artesanato e os trabalhos manuais voltaram a ter notoriedade e importância.

Valorizando o produto da região, a consequência é o aumento do fator econômico - fonte de renda para muitas famílias. Conforme Pesquisa de informações básicas municipais, realizada pelo IBGE (2015), entre as atividades artísticas, somente o artesanato se encontrava presente em 78,6\% das cidades brasileiras. Em 2006, esse percentual apresentava-se em $64,3 \%$. Os dados refletem a importância deste trabalho na geração da renda brasileira. Como comenta Souza e Queiroz (2015, p. 2):

[...] os produtos realizados por técnicas manuais são reconhecidos e despertam o interesse do Estado, que promove planos de desenvolvimento econômico para resgatar e dar continuidade a esse aspecto da cultura. Planos que visam fortalecer a cultura popular e preservá-la, desenvolver meios de comercializá-la e formas de melhorar a qualidade de vida nas comunidades, gerando emprego e renda.

No entanto, Porto Alegre (1994 apud SOUZA; QUEIROZ, 2015, p. 2) afirma que seria fundamental "existir uma expansão de um marketing cultural do lazer e turismo que alavanca a produção e venda desses produtos típicos ou regionais, assim, o resultado dessas políticas públicas contribui para o fortalecimento da identidade regional".

Porém, há muito a ser melhorado, necessitando de incentivos governamentais para o aperfeiçoamento e a propagação dessa mão de obra e dos produtos por ela desenvolvidos. No 
contexto apresentado, o papel do designer é muito importante, pois ele pode criar um elo entre as necessidades do mercado e o conhecimento das técnicas profissionais. Silva $(2011$, p. 171) reforça esta afirmação ao dizer que,

[...] estratégias e métodos adotados para a adequação dos produtos manuais, às exigências de mercado são aplicados pelos designers que trabalham diretamente com as associações. É o designer que vai estar em contato constante com a artesã para, assim, trabalhar o artesanato a fim de que este atenda às expectativas da sociedade de consumo.

Aos designers interessados, cabe preservar a cultura, buscar compreender mais sobre os meios, pensando sempre no que se é capaz de fazer dentro das técnicas e com as matérias-primas. Também pensar na capacidade da comunidade, em como se pode ajudar nesse trabalho. Esse tipo de abordagem pode ser por meio de diálogos, já que ambas as partes podem complementar o conhecimento uma da outra.

\subsection{Design e processo criativo}

De acordo com Potter (1980, p. 55, tradução nossa), encontram-se diversas definições de design, a principal e mais usada é a que se trata de uma atividade que confere "forma e ordem para atividades cotidianas". Desse modo, é uma atividade a qual envolve diversas e diferentes profissões, englobando o desenvolvimento de produtos, serviços, sistemas gráficos, interiores e arquitetura. O desenvolvimento do design compreende muita criatividade direcionada pelo processo. Assim, a criatividade é voltada para a produção de um produto prático e viável, resultado da solução para um problema.

O processo de design busca gerar ideias possíveis com uso de variadas técnicas que estimulem o designer a pensar e buscar por soluções criativas e inovadoras. Para Mozota, Klöpsch e Costa (2011), este processo criativo está relacionado a cinco etapas, onde cada uma delas tem um objetivo diferente e visa gerar resultados visuais elaborados. Inicia-se o processo na etapa 0 , ou etapa preliminar, que é a de Investigação, ou seja, a fase onde a oportunidade ou a necessidade é identificada, na qual começam a surgir ideias e quando se observa que esta necessidade pode ser convertida em um conceito de design. A etapa de número 1, chamada de Pesquisa, ocorre quando o designer analisa o briefing, identificando o problema e o objetivo do projeto. Nesse momento, 
além de avaliar a oportunidade e a importância do projeto para a empresa, são feitas perguntas diversas para assimilar os dados e a decisão que levou a empresa a lançar o projeto.

A etapa de número 2, chamada de Exploração, dá-se após compreender o problema. 0 designer com seus recursos criativos começa a fazer esboços de diferentes formas possíveis, as quais o projeto pode adquirir. A etapa de número 3, denominada Desenvolvimento, ocorre quando são apresentados os desenhos técnicos e as soluções escolhidas em três dimensões (3D). Os esboços em tamanho real possibilitam ao designer verificar se há restrições técnicas para a montagem do produto. Na etapa de número 4, a Realização, são feitos os testes e a confecção do protótipo para o projeto. Nessa etapa, o designer cria documentos para definir quais serão os materiais utilizados, a cor e o tratamento de superfície. A etapa 5, chamada Avaliações, envolve os controles técnicos, os testes de cálculo e a avaliação de mercado. Nessa etapa, o cliente pode pedir que o designer faça ilustrações, vistas do produto e documentos de comunicações.

Outros autores que tratam sobre processo de design e têm uma visão distinta sobre as etapas são Ambrose e Harris (2011). Para eles, o processo de design é dividido em 7 etapas, nas quais primeiro deve-se definir o problema e o público-alvo, ou seja, determinar o necessário para o projeto ser bem-sucedido. A segunda etapa, de pesquisa, analisa o histórico do problema, realiza levantamentos com usuários finais e identifica possíveis obstáculos. A etapa de número 3 , envolve as gerações de ideias, a partir das necessidades do consumidor final. A próxima etapa engloba os testes de protótipos, que tratam do desenvolvimento das ideias propostas anteriormente. A etapa de seleção trata das soluções analisadas em relação ao objetivo do briefing. A etapa de implementação foca no desenvolvimento e na entrega final à empresa. A etapa final de aprendizado auxilia os designers a aprimorar o desempenho, procurando obter os feedbacks do cliente e do público, analisando se a solução proposta atingiu os objetivos iniciais.

Observando os conceitos de processo de design, tanto apresentados por Mozota, Klöpsch e Costa (2011), quanto por Ambrose e Harris (2011), pode-se entender que ele consiste no mapeamento da visão e dos processos inseridos na vida dos indivíduos e visa obter um espectro completo sobre a solução de determinados problemas. Desta maneira, é possível identificar melhor as barreiras e, assim, gerar alternativas que sejam viáveis. Não parte de argumentos aleatórios, mas de levantamentos reais das necessidades do consumidor. Ao estabelecer um processo de design que defina objetivos claros, o designer pode analisar resultados e verificar o que poderá ser feito 
para chegar a resultados futuros, o que seria algo mais difícil de concretizar sem a utilização de um processo.

\section{DESENVOLVIMENTO DA PESQUISA}

Visando observar como os profissionais do artesanato e dos trabalhos manuais desenvolvem seus produtos e, assim, verificar se o design está presente nesse processo, a pesquisa iniciou com o mapeamento da região do Médio Vale do Itajaí. Nas regiões pesquisadas, notou-se que os artesões praticam mais do que uma técnica, sendo que alguns trabalhos se destacaram em certas regiões como: em Pomerode e em Botuverá as técnicas predominantes são as pinturas típicas da região; em Brusque e Guabiruba o patchwork e as bonecas de pano tem mais força; em Rio dos Cedros destaca-se a técnica do vime; em Gaspar, Timbó, Rodeio e Indaial é predominante a técnica do crochê e tricô; já em Blumenau os bordados ganham destaque.

$\mathrm{Na}$ etapa das entrevistas, um grande 'dificultador' foi contar com a participação de sujeitos na pesquisa, devido à disponibilidade e distância. Contou-se com a boa vontade e colaboração de 23 pessoas e para evitar a exposição, suas identidades foram mantidas em sigilo. Cada entrevista foi iniciada com as devidas apresentações, seguidas pela descrição das características da pesquisa, deixando claro ao entrevistado, o interesse e finalidade da investigação. Cada entrevista durou aproximadamente de 20 minutos e a compilação dos dados completos das entrevistas encontra-se no Quadro 1.

A busca pelo artesanato e pelo trabalho manual veio, principalmente, pelo próprio interesse de poder adquirir uma fonte de renda alternativa. Para se manter em constante aprendizado, muitos procuram por cursos na sua área e até mesmo buscam conhecer novas técnicas, a fim de levar diferenciação aos seus produtos. A profissão é uma extensão do que é considerado como a vocação da região. Observou-se que a grande maioria dos profissionais praticam e possuem o conhecimento de mais de uma técnica, conseguindo produzir muitos produtos, desde bolsas, toalhas, colchas, quadros, artefatos de decoração, dentre outros.

Quando Ihes foi perguntado como buscam inspirações para realizar seus trabalhos, cerca de $80 \%$ dos entrevistados comentaram que utilizam da internet e revistas. Contudo, destacaram que não fazem uma cópia fiel do que é visto, sempre modificam algo e dão seu toque particular. Alguns citaram que também se inspiram na própria cultura da região e na natureza. Apenas o 
entrevistado "S" comentou que busca muito de suas ideias a partir da mídia, acreditando que o artesanato não é apenas "o fuxico do interior".

Dentre tantos diferenciais que este trabalho pode agregar a um produto estão a qualidade, - acabamento e a exclusividade. O entrevistado " $\mathrm{P}$ " comentou que uma das principais características do artesanato é ter no artefato algo de quem o elaborou, mas, nos dias de hoje, existem diversos tipos de trabalhos em que se podem observar artesãos produzindo quase em escala. O entrevistado acredita faltar um pouco mais da identidade da pessoa no trabalho feito por ela. Ainda, quando indagado se o entrevistado concorda que o produto teria de ser algo mais exclusivo, o mesmo confirma que sim. Para ele, o artesão irá colocar uma característica sua naquele determinado trabalho. Completa que, muitos estão realizando artesanato apenas por meio de cópias de revistas, ficando tudo massificado, igual.

Uma ideia contrária do entrevistado " $P$ " é a dos entrevistados "B" e "D". Citam, como uma dificuldade, não poderem reproduzir peças em quantidades e variedades de cores e tamanhos. Outra dificuldade expressa nas entrevistas foi a falta de profissionais capacitados. Conforme o entrevistado "I", os artesões não qualificados produzem com preços baixos, gerando produtos sem acabamento, sem qualidade de materiais e apenas reproduzindo cópias, o que torna cada vez mais difícil a valorização de um bom trabalho artesanal.

A desvalorização foi um item ressaltado nas entrevistas. Para o entrevistado " $R$ ", o consumidor não sabe dar valor ao artesanato, o artesão investe dinheiro e tempo a fim de fazer uma peça boa e muitas vezes leva um dia inteiro ou mais para efetivar o produto, tendo custo alto e as pessoas nem sempre dão o devido valor que aquele produto realmente merece. Assim, dificilmente o artesão é recompensado pelo seu trabalho.

Ainda, os entrevistados " $F$ " e "K" afirmam que os consumidores não possuem a cultura do artesanato, não entendem o conceito da arte, a história do produto, o tempo investido da sua produção e o material de qualidade que foi utilizado, por isso não o valorizam. Quando se deparam com o preço, 'acham absurdo', pensam que poderia ser comprado no "1,99". O entrevistado "T" afirma que a dificuldade se encontra especialmente no preço, pois coloca-se um determinado valor maior pelo acabamento empregado, ou seja, por ser um produto melhor. Porém, alguns artesãos dizem fazer o mesmo pela metade do preço. Há, então, muitos consumidores que não entendem e 
acabam optando pelo mais barato, sem observar, por exemplo, a escolha do tecido, a combinação de cores, o detalhe ou o acabamento.

Desse modo, pôde-se observar que muitos profissionais ainda não trabalham integralmente com o artesanato como única fonte de renda devido a esta desvalorização. 0 entrevistado " $F$ " comentou que o artesanato não lhe dá o merecido retorno. Os entrevistados " $Q$ " e " $U$ " comentaram a falta de apoio de prefeituras e governo. O entrevistado " $U$ " enfatizou que a prefeitura oferece professores de artesanato para dar aulas nos bairros, porém a própria prefeitura não disponibiliza materiais como tecidos ou moldes. Ainda comentou que a prefeitura providencia feiras para a venda e amostra deste tipo de trabalho, mas o espaço é pequeno e não há divulgação do evento. Para ele, essa questão mostra a falta de interesse da prefeitura, que poderia procurar entender mais sobre as técnicas e de que maneira seria apropriado oferecer os cursos, além de ofertar um local adequado para a venda dos produtos.

Mesmo com todas as dificuldades e a desvalorização citadas, notou-se a emoção na fala de todos os entrevistados, a paixão pelo que fazem. Ficou evidenciado que não realizam seus trabalhos apenas pelo aspecto econômico e financeiro, mas também pela gratificação e pelo prazer de poder atuar no mercado com um produto próprio, de qualidade e exclusividade.

Quadro 1 - Resultado de entrevistas com profissionais da área de artesanato e trabalho manual do Médio Vale do Itajaí

\begin{tabular}{|c|c|c|c|c|c|c|c|c|c|c|c|}
\hline 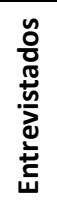 & 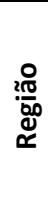 & 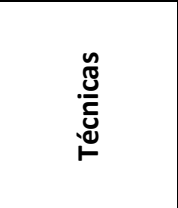 & 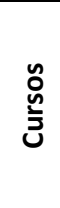 & 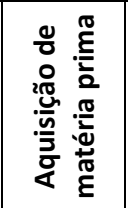 & $\begin{array}{l}\frac{n}{0} \\
\frac{\pi}{0}\end{array}$ & $\begin{array}{l}\tilde{0} \\
\frac{1}{5} \\
\frac{0}{2}\end{array}$ & 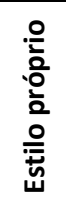 & 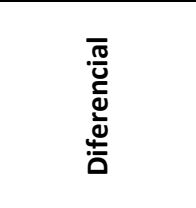 & $\begin{array}{l}\stackrel{0}{2} \\
\frac{0}{0} \\
0\end{array}$ & $\begin{array}{l}\frac{\pi}{0} \\
\frac{1}{0} \\
\end{array}$ & 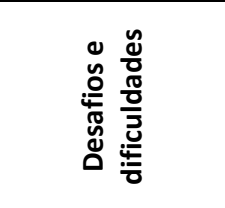 \\
\hline "A" & $\begin{array}{l}\frac{J}{\pi} \\
\frac{c}{d} \\
\frac{\varrho}{J} \\
\frac{J}{\infty}\end{array}$ & Patchwork & Sim & Lojas & $\begin{array}{c}\text { Necessi- } \\
\text { dade, } \\
\text { internet, } \\
\text { natureza, } \\
\text { pontos } \\
\text { turísticos }\end{array}$ & $\begin{array}{c}\text { Bolsas, } \\
\text { carteiras, } \\
\text { mochilas, } \\
\text { jogo } \\
\text { americano, } \\
\text { nécessaires }\end{array}$ & Sim & Qualidade & $\begin{array}{c}\text { Auxilia } \\
\text { na renda }\end{array}$ & $\begin{array}{c}\text { Facebook, } \\
\text { amigos e } \\
\text { mercado } \\
\text { livre }\end{array}$ & $\begin{array}{l}\text { Valorização, } \\
\text { reconhecimento }\end{array}$ \\
\hline "B" & 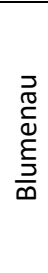 & $\begin{array}{c}\text { Bordado, } \\
\text { crochê, tricô } \\
\text { e pintura }\end{array}$ & Sim & $\begin{array}{c}\text { Lojas e } \\
\text { outros } \\
\text { profissio- } \\
\text { nais }\end{array}$ & $\begin{array}{l}\text { Necessi- } \\
\text { dade }\end{array}$ & $\begin{array}{c}\text { Roupa, } \\
\text { bolsa, } \\
\text { toalha, } \\
\text { nécessaire, } \\
\text { porta biju, } \\
\text { penais, } \\
\text { lancheiras }\end{array}$ & Sim & $\begin{array}{c}\text { Qualidade } \\
\text { e acabamento }\end{array}$ & Renda & Feiras & $\begin{array}{l}\text { Produzir em } \\
\text { quantidade }\end{array}$ \\
\hline
\end{tabular}




\begin{tabular}{|c|c|c|c|c|c|c|c|c|c|c|c|}
\hline "C" & 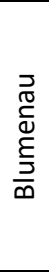 & Pintura & Sim & Lojas & Internet & \begin{tabular}{|c|} 
Bonecas, \\
coelhos, \\
bolsas, Noel, \\
placas para \\
lavabo, \\
porta \\
chaves \\
\end{tabular} & Sim & $\begin{array}{l}\text { História } \\
\text { da peça }\end{array}$ & Renda & $\begin{array}{c}\text { Loja na } \\
\text { Vila } \\
\text { Germânica }\end{array}$ & Não possui \\
\hline "D" & 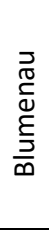 & Bordado & Sim & Lojas & $\begin{array}{l}\text { Ideia } \\
\text { própria }\end{array}$ & $\begin{array}{c}\text { Produtos } \\
\text { para } \\
\text { cozinha, } \\
\text { decoração, } \\
\text { mantas, } \\
\text { almofadas }\end{array}$ & Sim & $\begin{array}{l}\text { História } \\
\text { da peça }\end{array}$ & Renda & $\begin{array}{c}\text { Feiras e loja } \\
\text { na } \\
\text { Vila } \\
\text { Germânica }\end{array}$ & $\begin{array}{c}\text { Produzir em } \\
\text { quantidade, } \\
\text { variedades de } \\
\text { cores e tamanhos }\end{array}$ \\
\hline "E" & 要 & $\begin{array}{c}\text { Crochê, tricô, } \\
\text { bordado }\end{array}$ & Não & \begin{tabular}{|c|} 
Viés, \\
recolhe o \\
que iria \\
ser \\
jogado \\
no lixo
\end{tabular} & $\begin{array}{l}\text { Ideias } \\
\text { próprias }\end{array}$ & $\begin{array}{c}\text { Puxa saco, } \\
\text { toalhas, } \\
\text { roupas, } \\
\text { capas para } \\
\text { bebedor de } \\
\text { água }\end{array}$ & Não & $\mathrm{x}$ & $\begin{array}{l}\text { Passa- } \\
\text { tempo }\end{array}$ & Não vende & Valorização \\
\hline "F" & 䓠 & $\begin{array}{l}\text { Pintura em } \\
\text { quadros }\end{array}$ & Não & Lojas & $\begin{array}{c}\text { Natureza, } \\
\text { a partir de } \\
\text { uma } \\
\text { imagem }\end{array}$ & Quadros & Não & $\mathrm{x}$ & $\begin{array}{l}\text { Passa- } \\
\text { tempo }\end{array}$ & Não vende & $\begin{array}{c}\text { Povo não } \\
\text { tem cultura sobre } \\
\text { artesanato, não } \\
\text { valorização }\end{array}$ \\
\hline "G" & $\begin{array}{l}\frac{1}{\pi} \\
\frac{0}{n} \\
\text { ల } \\
0\end{array}$ & Tricô e crochê & Não & Lojas & $\begin{array}{l}\text { Internet e } \\
\text { ideias } \\
\text { próprias }\end{array}$ & $\begin{array}{l}\text { Roupas, } \\
\text { bolsas, } \\
\text { toalhas }\end{array}$ & Sim & $\begin{array}{l}\text { Produto feito à } \\
\text { mão, qualidade }\end{array}$ & Renda & $\begin{array}{c}\text { Feira e boca } \\
\text { a boca }\end{array}$ & Valorização \\
\hline "H" & $\begin{array}{l}\frac{\overline{0}}{\sqrt{\pi}} \\
\underline{0} \\
\underline{\underline{\Xi}}\end{array}$ & $\begin{array}{c}\text { Tricô, crochê, } \\
\text { bordado, } \\
\text { pintura }\end{array}$ & Sim & Loja & $\begin{array}{l}\text { Revista, } \\
\text { internet, } \\
\text { ideias } \\
\text { próprias }\end{array}$ & $\begin{array}{c}\text { Panos de } \\
\text { prato, } \\
\text { toalhas de } \\
\text { banho, } \\
\text { roupas em } \\
\text { tricô para } \\
\text { recém- } \\
\text { nascidos, } \\
\text { crochê. } \\
\text { Bordados, } \\
\text { echarpes, } \\
\text { gorros, } \\
\text { meias, } \\
\text { polainas, } \\
\text { roupas de } \\
\text { cama, } \\
\text { mantas, } \\
\text { decorações. }\end{array}$ & Sim & História & $\begin{array}{l}\text { Auxilia } \\
\text { na renda }\end{array}$ & $\begin{array}{c}\text { Feiras e } \\
\text { boca a boca }\end{array}$ & $\begin{array}{c}\text { Acredita que não } \\
\text { possui desafio }\end{array}$ \\
\hline "I" & $\begin{array}{l}\frac{0}{0} \\
\frac{0}{\pi} \\
\frac{1}{0} \\
0\end{array}$ & $\begin{array}{c}\text { Pintura } \\
\text { country e } \\
\text { bauernn- } \\
\text { malerei em } \\
\text { madeira } \\
\text { (pintura } \\
\text { campestre } \\
\text { alemã) }\end{array}$ & Sim & Loja & $\begin{array}{l}\text { Ideias } \\
\text { próprias }\end{array}$ & $\begin{array}{c}\text { Coelhos de } \\
\text { pascoa, } \\
\text { placa de } \\
\text { jardim, } \\
\text { moveis, } \\
\text { portas, } \\
\text { batedor de } \\
\text { manteiga, } \\
\text { bancos }\end{array}$ & Sim & $\begin{array}{l}\text { Peças únicas e } \\
\text { exclusivas }\end{array}$ & Renda & $\begin{array}{c}\text { Boca a boca } \\
\text { e lojas pela } \\
\text { cidade }\end{array}$ & $\begin{array}{c}\text { Competitividade, } \\
\text { não possui } \\
\text { profissionais } \\
\text { qualificados }\end{array}$ \\
\hline
\end{tabular}




\begin{tabular}{|c|c|c|c|c|c|c|c|c|c|c|c|}
\hline "J" & $\begin{array}{l}\frac{0}{0} \\
\frac{0}{\square} \\
\varepsilon \\
\frac{0}{0}\end{array}$ & $\begin{array}{l}\text { Pintura em } \\
\text { tecido e } \\
\text { madeira }\end{array}$ & Sim & $\begin{array}{c}\text { Lojas e } \\
\text { reutiliza } \\
\text { materiais }\end{array}$ & $\begin{array}{c}\text { Se inspira } \\
\text { na cultura } \\
\text { da região e } \\
\text { paisagens }\end{array}$ & \begin{tabular}{|c|} 
Roupa, \\
bolsa, \\
toalhas, \\
pano de \\
prato, \\
pinturas em \\
caixas para \\
decoração
\end{tabular} & $\begin{array}{c}\text { Sim, } \\
\text { possui } \\
\text { brasão } \\
\text { perso- } \\
\text { nalizado }\end{array}$ & $x$ & Renda & $\begin{array}{c}\text { Expõe o } \\
\text { trabalho em } \\
\text { lojas da } \\
\text { cidade }\end{array}$ & $\begin{array}{c}\text { Falta de material, } \\
\text { acredita que não } \\
\text { possui } \\
\text { desvalorização }\end{array}$ \\
\hline "K" & 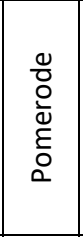 & Pintura & Sim & Lojas & \begin{tabular}{|c|} 
Na terra, \\
homem, \\
paisagem, \\
a partir de \\
uma \\
imagem \\
\end{tabular} & $\begin{array}{c}\text { Escultura e } \\
\text { quadros }\end{array}$ & $\begin{array}{c}\text { Sim, } \\
\text { impres- } \\
\text { sionista }\end{array}$ & Produtos únicos & Renda & $\begin{array}{l}\text { No seu } \\
\text { próprio } \\
\text { atelier }\end{array}$ & $\begin{array}{c}\text { Valorização, } \\
\text { consumidor não } \\
\text { entende o } \\
\text { conceito da arte }\end{array}$ \\
\hline "L" & $\left|\begin{array}{cc}n & 0 \\
0 & 0 \\
0 & \frac{0}{0} \\
\hdashline & 0 \\
\hdashline & 0\end{array}\right|$ & Vime & Não & Lojas & $\begin{array}{l}\text { Necessi- } \\
\text { dade e } \\
\text { revistas }\end{array}$ & $\begin{array}{l}\text { Móveis, } \\
\text { baú, } \\
\text { cesteira }\end{array}$ & Não & Qualidade & Renda & $\begin{array}{l}\text { Possui loja } \\
\text { própria }\end{array}$ & Crise \\
\hline "M" & $\begin{array}{l}\frac{0}{10} \\
\frac{0}{0} \\
\frac{1}{x}\end{array}$ & $\begin{array}{c}\text { Patchwork } \\
\text { e tricô }\end{array}$ & Sim & Lojas & $\begin{array}{c}\text { Revista, } \\
\text { internet e } \\
\text { feiras }\end{array}$ & $\begin{array}{c}\text { Patchwork } \\
\text { tradicional } \\
\text { (bonecos, } \\
\text { toalhas de } \\
\text { rosto e } \\
\text { lavabo, } \\
\text { trilhos de } \\
\text { mesa e } \\
\text { balcão, } \\
\text { nécessaire, } \\
\text { bolsas, } \\
\text { lixeirinha de } \\
\text { carro, capa } \\
\text { galão de } \\
\text { água } \\
\text { e outros) } \\
\text { tricô } \\
\text { (cachecóis, } \\
\text { polainas, } \\
\text { luvas, } \\
\text { meias, } \\
\text { golas). } \\
\end{array}$ & Sim & Trabalhos únicos & $\begin{array}{l}\text { Auxilio } \\
\text { na renda }\end{array}$ & $\begin{array}{c}\text { Feiras, } \\
\text { Facebook, } \\
\text { boca a boca }\end{array}$ & $\begin{array}{c}\text { Valorização } \\
\text { e entendimento } \\
\text { do consumidor } \\
\text { na hora do preço }\end{array}$ \\
\hline "N" & 总 & $\begin{array}{c}\text { Crochê, } \\
\text { pintura, tricô } \\
\text { e bordados }\end{array}$ & Sim & Loja & \begin{tabular}{|} 
Revistas e \\
ideias \\
próprias
\end{tabular} & $\begin{array}{l}\text { Bolsa, } \\
\text { toalhas }\end{array}$ & Não & $x$ & Renda & Feira & Valorização \\
\hline "O" & 送 & Patchwork & Sim & Loja & $\begin{array}{c}\text { Revistas e } \\
\text { ideias } \\
\text { próprias }\end{array}$ & \begin{tabular}{|c|} 
Toalha, capa \\
de \\
almofada, \\
kit cozinha, \\
colcha
\end{tabular} & Não & Exclusividade & Renda & $\begin{array}{c}\text { Apenas } \\
\text { por } \\
\text { encomenda }\end{array}$ & $\begin{array}{c}\text { Valorização } \\
\text { e entendimento } \\
\text { do consumidor }\end{array}$ \\
\hline "P" & $\begin{array}{l}\frac{0}{2} \\
\frac{0}{0} \\
\frac{n}{0}\end{array}$ & Patchwork & Sim & Lojas & \begin{tabular}{|} 
Revistas \\
importadas \\
,ideias \\
próprias
\end{tabular} & \begin{tabular}{|c|} 
Colchas, \\
toalhas, \\
decoração, \\
almofada
\end{tabular} & Sim & \begin{tabular}{|} 
Poder passar ao \\
produto sua \\
identidade \\
e a qualidade
\end{tabular} & Renda & $\begin{array}{c}\text { Encomen- } \\
\text { das }\end{array}$ & $\begin{array}{l}\text { Valorização, } \\
\text { profissionais } \\
\text { capacitados } \\
\text { e produção em } \\
\text { quantidade }\end{array}$ \\
\hline "Q" & $\begin{array}{l}\frac{0}{2} \\
\frac{0}{0} \\
\frac{\cos }{2}\end{array}$ & \begin{tabular}{|} 
Luminárias \\
rústicas feita \\
com canoa do \\
cacho do \\
coqueiro
\end{tabular} & Não & $\begin{array}{c}\mathrm{Da} \\
\text { natureza }\end{array}$ & $\begin{array}{c}\text { Na própria } \\
\text { natureza }\end{array}$ & Luminárias & $\operatorname{Sim}$ & $\begin{array}{l}\text { Diferente e } \\
\text { inovador }\end{array}$ & $\begin{array}{l}\text { Auxilia } \\
\text { na renda }\end{array}$ & $\begin{array}{c}\text { Feiras, } \\
\text { encomen- } \\
\text { das, } \\
\text { Facebook }\end{array}$ & $\begin{array}{c}\text { Falta de incentivo } \\
\text { do governo } \\
\text { federal, estadual } \\
\text { e municipal }\end{array}$ \\
\hline
\end{tabular}




\begin{tabular}{|c|c|c|c|c|c|c|c|c|c|c|c|}
\hline "R" & $\begin{array}{l}\frac{0}{D} \\
\frac{0}{5} \\
\frac{1}{2} \\
\infty\end{array}$ & Bonecas & Sim & Lojas & $\begin{array}{c}\text { Revistas e } \\
\text { internet }\end{array}$ & $\begin{array}{c}\text { Bonecas de } \\
\text { pano, } \\
\text { almofadas, } \\
\text { bichinhos }\end{array}$ & Sim & $\begin{array}{l}\text { Qualidade, } \\
\text { exclusividade }\end{array}$ & Renda & $\begin{array}{c}\text { Boca a boca } \\
\text { e encomen- } \\
\text { das }\end{array}$ & Valorização \\
\hline "S" & $\begin{array}{l}\frac{0}{D} \\
\frac{0}{5} \\
\frac{1}{2} \\
\infty\end{array}$ & $\begin{array}{l}\text { Patchwork, } \\
\text { madeira }\end{array}$ & Sim & Lojas & $\begin{array}{c}\text { Mídia e } \\
\text { tendências }\end{array}$ & \begin{tabular}{|c|} 
Almofadas, \\
caixas de \\
madeiras, \\
decoração, \\
bolsas, \\
roupas
\end{tabular} & Sim & $\begin{array}{c}\text { Qualidade, peça } \\
\text { única, colocar } \\
\text { sua identidade } \\
\text { no produto }\end{array}$ & Renda & $\begin{array}{c}\text { Facebook, } \\
\text { boca a boca } \\
\text { e encomen- } \\
\text { das }\end{array}$ & $\begin{array}{c}\text { Valorização, } \\
\text { entendimento do } \\
\text { consumidor, } \\
\text { profissionais } \\
\text { capacitados }\end{array}$ \\
\hline "T" & 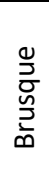 & $\begin{array}{l}\text { Patchwork, } \\
\text { madeira, } \\
\text { bonecas, } \\
\text { bordado }\end{array}$ & Sim & Lojas & $\begin{array}{l}\text { Internet, } \\
\text { revista }\end{array}$ & $\begin{array}{c}\text { Bonecas, } \\
\text { bolsas, } \\
\text { toalhas }\end{array}$ & Sim & $\begin{array}{l}\text { Exclusividade, } \\
\text { personalizado }\end{array}$ & $\begin{array}{l}\text { Auxilia } \\
\text { na renda }\end{array}$ & $\begin{array}{c}\text { Facebook } \\
\text { e boca a } \\
\text { boca }\end{array}$ & $\begin{array}{c}\text { Valorização, } \\
\text { concorrência de } \\
\text { preço, } \\
\text { profissionais } \\
\text { capacitados }\end{array}$ \\
\hline "U" & $\begin{array}{l}\frac{0}{D} \\
\frac{0}{5} \\
\frac{1}{n} \\
\infty\end{array}$ & $\begin{array}{c}\text { Tricô, crochê, } \\
\text { bordado, } \\
\text { bonecas, } \\
\text { pintura }\end{array}$ & Sim & $\begin{array}{c}\text { Utiliza de } \\
\text { reciclado } \\
\text { s e lojas }\end{array}$ & $\begin{array}{l}\text { Internet, } \\
\text { próprias } \\
\text { ideias, } \\
\text { revista }\end{array}$ & $\begin{array}{c}\text { Bonecas, } \\
\text { colchas, } \\
\text { bolsas, } \\
\text { almofadas, } \\
\text { decorações, } \\
\text { roupas, tiara } \\
\text { de cabelo }\end{array}$ & Sim & $\begin{array}{l}\text { Qualidade, } \\
\text { exclusividade }\end{array}$ & Renda & $\begin{array}{c}\text { Boca a } \\
\text { boca, } \\
\text { encomen- } \\
\text { das e } \\
\text { Facebook }\end{array}$ & $\begin{array}{c}\text { Valorização, } \\
\text { entendimento do } \\
\text { consumidor }\end{array}$ \\
\hline
\end{tabular}

Fonte: elaborado pela autora Pianizzer (2016).

Os autores Mozota, Klöpsch e Costa (2011) e Ambrose e Harris (2011) tratam os conceitos do processo de design com etapas similares. Iniciam o projeto com a definição de um problema, para posteriormente fazer uma pesquisa e adquirir informações sobre o histórico do problema. $\mathrm{Na}$ terceira etapa, são geradas as ideias ou os esboços e na quarta etapa, ocorre o desenvolvimento do projeto. Com o projeto já desenvolvido, na quinta etapa dá-se a realização dos testes e analisam-se as soluções propostas. As fases propostas por Mozota, Klöpsch e Costa (2011) encerram-se na sexta etapa, quando o produto é fabricado e entregue para o cliente. Para Ambrose e Harris (2011), ainda resta uma etapa, mas não menos importante, a que chamam de aprendizado, onde os designers buscam o feedback de seus clientes a fim de ajudá-los a aprimorar o desempenho.

A partir dos conceitos observados destes autores, pôde-se constatar por meio das entrevistas, ausência de etapas do processo criativo. Os projetos desenvolvidos pelos profissionais entrevistados iniciam por ideias encontradas em pesquisas realizadas nos meios virtuais e revistas, fazendo produtos de resultado similar ao que pesquisaram. Como não procuram entender seu público, não há a definição de um problema ou uma necessidade, logicamente desconhecem a melhor forma para solucioná-lo. Pôde-se observar também que não realizam gerações de alternativas, esboços dos projetos ou protótipos. Os profissionais partem da ideia já para a realização final do produto. Não desenvolvem, ainda, testes de combinações de cores ou testes de 
usabilidade. Em vista disso, percebeu-se que os profissionais não compreendem que, utilizando processos de design em seu trabalho, pode-se criar soluções mais criativas e, portanto, diminuir o risco de um produto não ficar satisfatório. Ficou evidenciado o desconhecimento da contribuição do design quanto à melhoria dos produtos.

Entende-se a carência de informação sobre os processos criativos e o design ocorrida devido à falta de formação profissional dos mesmos. Logo, o design é uma peça importante no trabalho desses profissionais, que apenas necessitam de um apoio para compreender como o design possui capacidade para contribuir com o desenvolvimento desse tipo de trabalho, por possibilitar a aplicação de elementos para a qualificação e valorização do produto frente ao mercado, sem comprometer as características das técnicas, as quais devem ser preservadas.

\section{CONSIDERAÇÕES FINAIS}

A pesquisa teve o intuito de mapear a região do Médio Vale do Itajaí em busca de profissionais da área do artesanato e trabalhos manuais, para entender quem eram estes profissionais, quais materiais utilizavam, como surgiam suas ideias e como era o processo criativo do seu produto. Ainda, se questionar em qual momento o design é levado em consideração, ou não, por esses profissionais. Buscou-se saber se este trabalho, segundo os profissionais, é valorizado e quais são os seus maiores desafios e dificuldades em atuar nesta área. Assim, pôde ser observada a importância da inclusão do design criativo como uma solução para melhoria no desenvolvimento desses produtos.

Nas entrevistas realizadas na região do Médio Vale do Itajaí, ficou evidenciado que os profissionais prezam pelo que fazem, mesmo que, segundo eles, este trabalho não seja devidamente valorizado e reconhecido pelo consumidor. Notou-se, na fala dos entrevistados, a falta do apoio de prefeituras e governos com incentivos para o tipo de trabalho desenvolvido e capacitação dos profissionais para a qualificação na área. Quando se trata de design, ficou evidente o desconhecimento dos profissionais quanto à sua contribuição para melhoria de seus produtos. Desse modo, existem possibilidades a serem criadas e desenvolvidas envolvendo educação, design, tecnologia e trabalhos manuais. Esses produtos representam o trabalho de uma longa jornada e envolvem diversos recursos, tais quais a biodiversidade, os costumes e o modo de fazer tradicional. 
Entender a qualidade desses produtos originais, ricos em cultura e significado, e conseguir compartilhá-los com a sociedade, que na maioria das vezes não reconhece o contexto de origem e a história do produto, é uma tarefa difícil, a qual requer sensibilidade e responsabilidade.

Com a globalização, o maior desafio e papel principal de contribuição do design para impulsionar os produtos de território e valorizar o patrimônio cultural, é identificar e compreender os valores e qualidades locais, captando seu modo de produção e seus significados. Em busca de incentivar a economia local, valorizando e promovendo essa mão-de-obra de modo a gerar parcerias com criadores e trazer benefícios à comunidade, parece ser o caminho para, no futuro, ser proporcionado o conhecimento em torno novas possibilidades a fim de irão motivar outros grupos e associações a investirem no potencial da comunidade.

\section{REFERÊNCIAS}

AMBROSE, Gavin; HARRIS, Paul. Design Thinking: s.m. ação ou prática de pensar o design. Porto Alegre: Bookman, 2011.

BRAGA, João; NUNES, Mônica. Reflexões sobre moda. 3. ed. rev. São Paulo: Anhembi Morumbi, 2006. 4 v.

BRASIL. Ministério do Desenvolvimento, Indústria e Comércio Exterior. Secretaria de Comércio e Serviços. Portaria $\mathbf{n}^{\circ} \mathbf{2 9}$, de 05 de outubro de 2010. Torna pública a base conceitual do artesanato brasileiro para padronizar e estabelecer os parâmetros de atuação do Programa do Artesanato Brasileiro - PAB em todo o território nacional. Diário Oficial da União: seção 1, Brasília, DF, n. 192, p. 100-102, 06 out. 2010. Disponível em:

http://pesquisa.in.gov.br/imprensa/jsp/visualiza/index.jsp?data=06/10/2010\&jornal=1\&pagina=10 0\&totalArquivos=152. Acesso em: 15 jul. 2019.

BRASIL. Ministério do Desenvolvimento, Indústria e Comércio Exterior. Secretaria Especial da Micro e Pequena Empresa. Portaria $n^{\circ}$ 1.007-sei, de 11 de junho de 2018. Institui o Programa do Artesanato Brasileiro, cria a Comissão Nacional do Artesanato e dispõe sobre a base conceitual do artesanato brasileiro. Diário Oficial da União: seção 1, Brasília, DF, n. 147, p. 34.01 ago. 2018. Disponível em: http://www.in.gov.br/materia//asset_publisher/Kujrw0TZC2Mb/content/id/34932949/do1-2018-08-01-portaria-n-1-007-sei-de11-de-junho-de-2018-34932930. Acesso em: 22.07.2019

DE CARLI, Ana Mery Sehbe et al. Design e artesanato: novidade e tradição, um diálogo possível. Revista Design, Inovação e Gestão Estratégica, Caxias do Sul, v. 2, n. 2, p. 430-444, 2011. 
FLORIT, Luciano Félix. A natureza do político e a política na natureza: notas sobre as implicações políticas da construção social da natureza e das chamadas vocações regionais. Cadernos IPPUR/UFRJ, 2009. No prelo.

IBGE. Perfil dos estados e dos municípios brasileiros: cultura: 2014. Rio de janeiro: IBGE, 2015. Disponível em: https://biblioteca.ibge.gov.br/visualizacao/livros/liv95013.pdf. Acesso em: 15 jul. 2019.

IBGE. Atlas do censo demográfico 2010. Rio de Janeiro: IBGE, 2013a. Disponível em: https://censo2010.ibge.gov.br/apps/atlas/. Acesso em: 15 jul. 2019.

IBGE. Sistema de informações e indicadores culturais: 2007-2010. Rio de Janeiro, IBGE: 2013 b. (Estudos e pesquisas: informação demográfica e socioeconômica, n. 31).

KRUCKEN, Lia. Design e território: valorização de identidades e produtos locais. São Paulo: Studio Nobel, 2009.

MOZOTA, Brigitte Borja de; KLÖPSCH, Cássia; COSTA, Filipe Campelo Xavier da. Gestão do design: usando o design para construir valor de marca e inovação corporativa. Porto Alegre: Bookman, 2011.

MOURA, Mônica. O contemporâneo no Design brasileiro: reflexão sobre objetos. In: CONGRESSO INTERNACIONAL DE DESEÑO, 1., 2012, Córdoba. Anais [...]. Córdoba: CIDI, 2012. p. 1-6. Disponível em: https://www.academia.edu/4577176/O_Contempor\%C3\%A2neo_no_Design_Brasileiro. Acesso em: 15 jul. 2019.

POTTER, Norman. What is a designer?: things, places, messages. London: Hyphen Press. 1980.

SILVA, Emanuelle Kelly Ribeiro da. Quando a cultura entra na moda: mercantilização do artesanato e suas repercussões no cotidiano de bordadeiras de Maranguape. Fortaleza: Edições UFC, 2011.

SOUZA, Kássia; QUEIROZ, Cyntia. Moda, design e artesanato. In: COLÓQUIO DE MODA, 11., 2015, Curitiba. Anais [...]. Curitiba: ABEPEM, 2015. p. 1-8. Disponível em: http://www.coloquiomoda.com.br/anais/anais/11-Coloquio deModa_2015/COMUNICACAOORAL/CO-EIXO3-CULTURA/CO-3-MODA-DESIGN-E-ARTESANATO.pdf. Acesso em: 15 jul. 2019.

WEBER, Max. A ética protestante e o espírito do capitalismo. São Paulo: Livraria Pioneira, 1967. 